Gazi University
Journal of Science
http://dergipark.gov.tr/gujs

\title{
Use of Ultrasound to Prepare Permeable Crosslinked PVA Membranes
}

\author{
Gulsen ASMAN ${ }^{1, *}$, Gulsen TASKIN CAKICI ${ }^{2}$, ${ }^{(1)}$ Ebru KONDOLOT SOLAK ${ }^{3}$ (D) Kannan SIVAPRAKASAM $^{4}$ \\ ${ }^{1}$ Gazi University, Faculty of Science, Department of Chemistry, 06500 Teknikokullar, Ankara, Turkey \\ ${ }^{2}$ Cumhuriyet University, Department of Chemistry and Chemistry Processing Technology, Ylldizeli, Sivas, Turkey \\ ${ }^{3}$ Gazi University, Technical Sciences Vocational School, Department of Chemistry and Chemical Processing Technology, Ostim, Ankara, Turkey \\ ${ }^{4}$ St.Cloud State University, Department of Chemistry and Biochemistry, $7204^{\text {th }}$ Ave South, St. Cloud MN 56301-4498, United States
}

\section{Highlights}

- Ultrasonication as a green alternative technique to enhance membrane permeability.

- Combined effect of nanofillers and ultrasonication.

- Effect of ultrasonication and nanofillers on crosslinked-PVA membranes.

\begin{tabular}{l} 
Article Info \\
Received: $31 / 01 / 2019$ \\
Accepted: 03/07/2019 \\
Keywords \\
\hline Green chemistry \\
ultrasound membrane \\
PVA \\
n-SiO \\
n-Ag
\end{tabular}

\section{INTRODUCTION}

PVA is a non-toxic, chemically stable, biocompatible polyhydroxy polymer and it has good film forming ability and high hydrophilicity [1,2]. Although PVA membranes have been commonly preferred for their high affinity toward water, especially in dehydration and separation processes [3-8], they have poor physical stability in water. So, the preparation of hydrophilic, highly permeable, water-insoluble PVA membranes is an important challenge. Crosslinking process is commonly used to improve their physical stability in aqueous systems [4, 9-12]. However, crosslinking process reduces the hydrophilicity of PVA membranes as well as their permeability. Although several alternative modifications have been used to address the reduced hydrophilicity and permeability of c-PVA membranes, e.g., grafting $[2,5,13,14]$, blending $[5,8$, 14] and filling with fine inorganic particles [1, 15-21], the use of efficient, eco-friendly green methods for the preparation of c-PVA membranes to minimize or eliminate undesired chemicals [22-27] is important, since in the last decade, increasing environmental awaerness needs to use eco-friendly methods.

Sonochemistry is used in membrane technology as a new branch of chemistry because of it is defined as a green and effective method [28-29]. The attractive application of ultrasonication (US) in membrane technology is seen in the determination of fouling layer (cake layer) thickness [30], pore shape and pore size [31] as well as porosity [32]. Its general use is found in filtration processes to clean or protect membrane surfaces from cake layer formations [33-39]. The application of US to solid phase membranes to enhance 
their permeabilities is one of the most interesting usages of sonication. However, there are only limited numbers of studies to enhance the permeabilities of the membranes by using US [17, 40-43]. Asman et al. [17] studied the effect of sonication on the release of theophylline by using cellulose acetate (CA) and n$\mathrm{SiO}_{2} / \mathrm{CA}$ membranes. They determined that ultrasonic-treatment enhances the permeability of theophylline through the membranes and increases their water-sorption abilities. Masselin et al. [40], studied the effect of sonication on polyethersulfone (PES), polyvinylidenefluoride (PVDF) and polyacrylonitrile (PAN) membranes; by their study it is deduced that, PES film is mainly affected by the ultrasonic treatment over all its surface. Wang et al. [41] tried to synthesize T-type zeolite membranes by using ultrasonic-assisted pretreatment preceding the hydrothermal synthesis; as a result of their study the synthesis time of the membranes becomes shorter and greater separation factor as well as the flux was obtained. Julian and Zentner [42] examined the effect of ultrasonic-assisted permeation of hydrocortisone and benzoic acid and have concluded that the permeability of the films can be increased by ultrasonic irradiation. Kost et al. [43] examined ultrasound-induced drug release behaviors of implant matrix systems. They have concluded that ultrasound leads to the degradation of the polymers and increases the release rate of incorporated molecule of the system.

The present work deals with the effect of US on the permeation characteristics of the crosslinked PVA membranes. For this aim, US was applied for the first time to c-PVA membranes as a green membrane treatment method to improve permeabilities of the membranes. Additionally, the combined effect of nanofillers and US on the characteristic properties of c-PVA membranes was also investigated. Swelling studies and water-contact angle (CA) measurements were used to determine hydrophilicity and water sorption tendency of the membranes. Characterizations of the membranes was done by SEM, XPS (ESCA) and DSC analysis. Permeation studies were performed by simple diffusion method Rhodamine-b (RB) and $\mathrm{Fe}^{3+}$ were preferred as model compounds in the study.

\section{EXPERIMENTAL}

\subsection{Materials}

PVA $\left(\mathrm{M}_{\mathrm{n}}, 72000 \mathrm{~g} / \mathrm{mol}\right), \mathrm{RB}$, analytical grades of $\mathrm{Na}_{2} \mathrm{SO}_{4}, \mathrm{KOH}$ and $\mathrm{FeCl}_{3} \cdot 6 \mathrm{H}_{2} \mathrm{O}$ were purchased from Merck Chemicals Ltd., UK. Nanopowders of silica $(10 \mathrm{~nm})$ and silver $(<90 \mathrm{~nm})$ were obtained from Aldrich.

\subsection{Membrane Preparation}

Membranes were prepared by casting method [44-46]. A predetermined amount of an aqueous solution of PVA $(5 \%(\mathrm{~m} / \mathrm{v}))$ was placed onto petri dishes and it was dried in an incubator at $40^{\circ} \mathrm{C}$ till to complete dryness was obtained. The dried membranes were immersed in aqueous $\mathrm{KOH}$ solution $(75 \mathrm{~g} / \mathrm{L})$, which was saturated with $\mathrm{Na}_{2} \mathrm{SO}_{4}$ for crosslinking process [47] to prepare the c-PVA membranes.

Crosslinked composite PVA membranes $\left(\mathrm{SiO}_{2} / \mathrm{c}\right.$-PVA and $\left.\mathrm{Ag} / \mathrm{c}-\mathrm{PVA}\right)$ were prepared by using the technique used for the preparation of c-PVA membranes. In this case, $\mathrm{n}_{-} \mathrm{SiO}_{2}$ and $\mathrm{n}$ - $\mathrm{Ag}$ was added to the aqueous PVA solution $(5 \%(\mathrm{~m} / \mathrm{v}))$ at a percent composition of $10 \%\left(\mathrm{~m}_{\text {filler }} / \mathrm{m}_{\mathrm{PVA}}\right)$ respectively and homogeneous nanofiller/PVA solution was used as casting solution.

In order to prepare US-treated c-PVA, $\mathrm{SiO}_{2} / \mathrm{c}-\mathrm{PVA}$ and $\mathrm{Ag} / \mathrm{c}-\mathrm{PVA}$ membranes (called as US-c-PVA, US$\mathrm{SiO}_{2} / \mathrm{c}-\mathrm{PVA}$ and US-Ag/c-PVA membranes, respectively) corresponding crosslinked membrane was subjected to ultrasonic waves in a sonicator (X-traH Elma, Germany), at a frequency of $35 \mathrm{kHz}$ and an input power of $160 \mathrm{~W}$. Sonication process was carried out in a thermostated water bath, for a constant period of 60 min. Membrane thicknesses ( $l$ ) were determined using a micrometer (Aldrich, Germany) and at least ten point measurements was used to determine the average membrane thicknesses. The abbreviations of the different membranes are listed in Table 1. 
Table 1. Definition of the membranes

\begin{tabular}{|l|l|}
\hline Membrane & Definition \\
\hline c-PVA & Crosslinked PVA membrane \\
\hline US-c-PVA & US-treated c-PVA membrane \\
\hline $\mathrm{SiO}_{2} / \mathrm{c}-\mathrm{PVA}$ & Crosslinked $\mathrm{n}-\mathrm{SiO}_{2} / \mathrm{PVA}$ composite membrane \\
\hline $\mathrm{US}-\mathrm{SiO}_{2} / \mathrm{c}-\mathrm{PVA}$ & US-treated $\mathrm{SiO}_{2} / \mathrm{c}-\mathrm{PVA}$ membrane \\
\hline $\mathrm{Ag} / \mathrm{c}-\mathrm{PVA}$ & Crosslinked $\mathrm{n}-\mathrm{Ag} / \mathrm{PVA}$ composite membrane \\
\hline $\mathrm{US}-\mathrm{Ag} / \mathrm{c}-\mathrm{PVA}$ & US-treated $\mathrm{Ag} / \mathrm{c}-\mathrm{PVA}$ membrane \\
\hline
\end{tabular}

\subsection{Membrane Characterization}

The membrane hydrophilicities and water sorption tendencies were determined by swelling studies and water contact angle measurements. The swelling ratio $\left(S_{w}\right)$ values of the membranes were calculated by Equation (1) [48], where, $W_{w}$ and $W_{d}$ are the wet and dry weights of the membranes respectively.

$$
S_{w}=\left(W_{w^{-}} W_{d}\right) / W_{d}
$$

Contact angle micrometer (Surface Electro Optics PHX 150) was used to investigate the interaction of the membrane surface with water. The reflected CA values were the averages of the measured angles at both side of the drop.

Morphological and thermal analysis of the membrane samples were analyzed using SEM, X-ray photoelectron spectroscopy (XPS, ESCA) and DSC techniques. For the SEM images of the membranes, the samples were dried and sputtered with $\mathrm{Au} / \mathrm{Pd}$ in vacuum, before viewing by SEM (Quanta-400 FESEM Analyzer (FES Company). ESCA (XPS) analysis was done by using PHI-5000-VersaProbe ESCA (XPS).

DSC analysis was performed using Perkin Elmer system to determine the thermal behavior of the membranes. Typical sample weight was $\sim 5 \mathrm{mg}$ and the samples were analyzed at a heating rate of $5{ }^{\circ} \mathrm{C} /$ min under $\mathrm{N}_{2}$ atmosphere.

\subsection{Permeation Studies}

Permeation studies for aqueous solutions of RB (50 ppm) and $\mathrm{Fe}^{3+}(0.01 \mathrm{M})$ were performed against distilled water at constant temperature, using a two-compartment horizontal diffusion cell. Sampling of the acceptor solution was done at definite time intervals and the aliquots were replaced by an equal amount of distilled water. Analysis of the $\mathrm{RB}$ and $\mathrm{Fe}^{3+}$ samples was done spectrophotometrically at $553 \mathrm{~nm}$ and $238 \mathrm{~nm}$, respectively.

\section{RESULTS AND DISCUSSION}

\subsection{Effect of the Presence of $\mathrm{n}-\mathrm{SiO}_{2}$ and $\mathrm{n}-\mathrm{Ag}$ on the Hydrophilicity of the c-PVA Membranes}

c-PVA, Ag/c-PVA and $\mathrm{SiO}_{2} / \mathrm{c}$-PVA membranes were casted at a controlled thickness of $50 \pm 5 \mu \mathrm{m}, 70 \pm 5 \mu \mathrm{m}$ and $130 \pm 5$ to investigate the effect of the presence of $n-\mathrm{SiO}_{2}$ and $\mathrm{n}-\mathrm{Ag}$ on the hydrophilic character of the crosslinked PVA membranes. For this aim, the swelling ratio values $\left(S_{\mathrm{w}}\right)$ of the membranes were computed by using Equation (1) and the results are shown in Table 2. 
Table 2. Swelling behaviours of the membranes

\begin{tabular}{|l|c|c|c|}
\hline & \multicolumn{3}{|c|}{$\boldsymbol{S}_{\boldsymbol{w}}(\mathbf{m} / \mathbf{m})$} \\
\hline $\boldsymbol{l}(\boldsymbol{\mu m})$ & $\mathbf{5 0} \pm \mathbf{5}$ & $\mathbf{7 0} \pm \mathbf{5}$ & $\mathbf{1 3 0} \pm \mathbf{5}$ \\
\hline $\mathrm{c}-\mathrm{PVA}$ & 1.53 & 1.42 & 1.36 \\
\hline $\mathrm{Ag} / \mathrm{c}-\mathrm{PVA}$ & 1.64 & 1.65 & 1.49 \\
\hline $\mathrm{SiO}_{2} / \mathrm{c}-\mathrm{PVA}$ & 1.90 & 1.84 & 1.74 \\
\hline $\mathrm{US}-\mathrm{Ag} / \mathrm{c}-\mathrm{PVA}$ & 2.15 & 2.08 & 1.86 \\
\hline $\mathrm{US}-\mathrm{SiO}_{2} / \mathrm{c}-\mathrm{PVA}$ & 2.35 & 2.28 & 2.16 \\
\hline
\end{tabular}

Table 2 shows that, $\mathrm{Ag} / \mathrm{c}$-PVA and $\mathrm{SiO}_{2} / \mathrm{c}$-PVA membranes have greater swelling vaues than c-PVA for each thickness. Increase in swelling by the presence of fillers suggests that both $\mathrm{n}-\mathrm{Ag}$ and especially $\mathrm{n}-\mathrm{SiO}_{2}$ increases the water sorption tendency, i.e., hydrophilicity of the c-PVA membranes. Increase in the membrane hydrophilicity in the presence of $\mathrm{SiO}_{2}$ most probably resulted from the high polar character of the $\mathrm{Si}-\mathrm{O}$ bond of $\mathrm{SiO}_{2}$, which attracts water molecules and makes membrane material more hydrophilic [49].
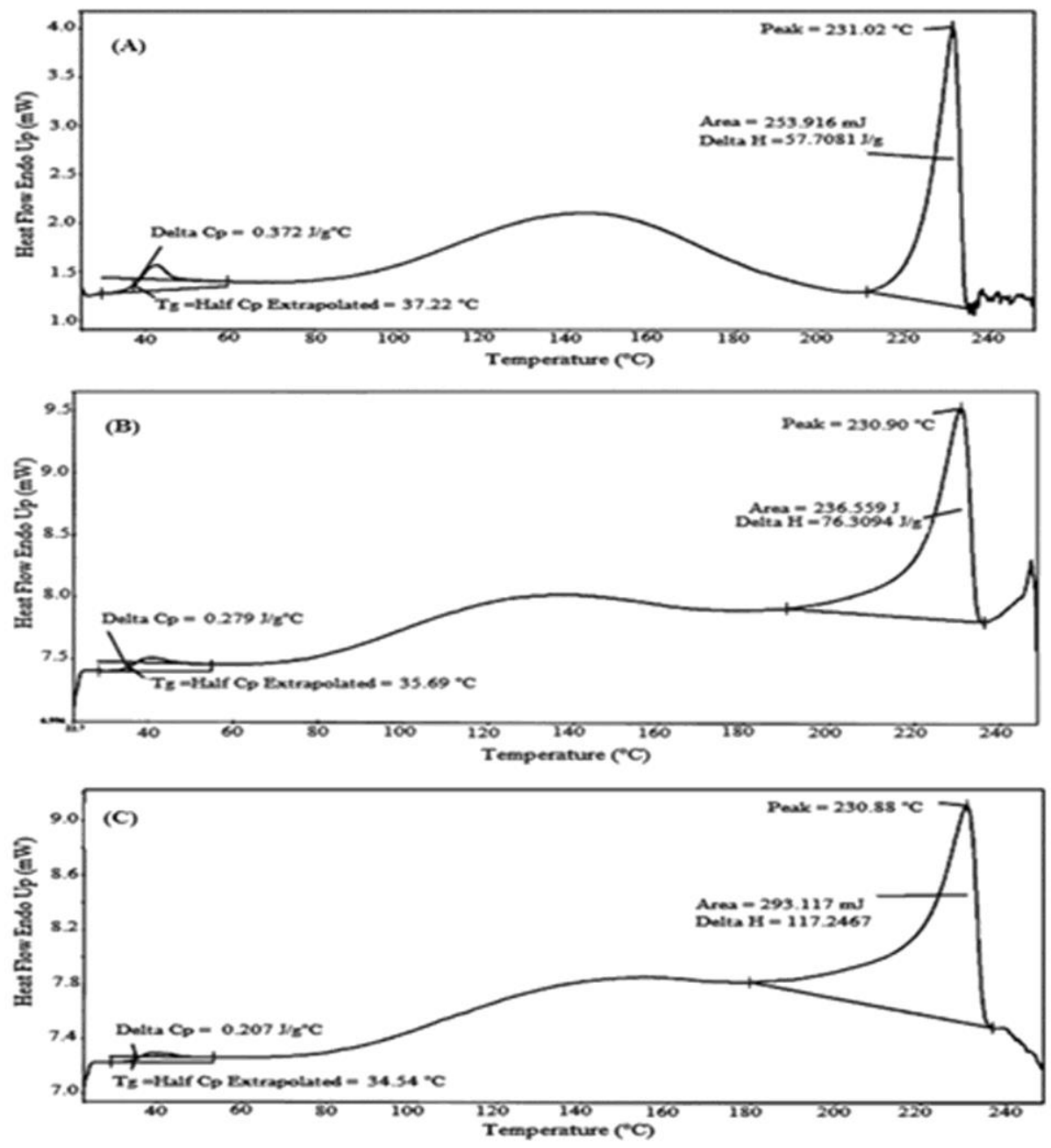

Figure 1. DSC thermogram of (A) c-PVA, (B) Ag/c-PVA and (C) $\mathrm{SiO}_{2} / c-P V A$ membranes

The enhancement in the hydrophilicity of the membranes is resulted from the interaction of Ag with water molecules via Ag-O interactions [50]. Bi et al. [51] investigated that $\mathrm{SiO}_{2}$ containing nafion membranes showed good water uptake and retention characteristics. Meng and Sun [52] reported that the presence of 
$\mathrm{Ag}$ in $\mathrm{TiO}_{2}$ films decreases the water contact angle values of the films, indicating increase in the hydrophilic character of the films. Watanabe et al. [53] used nafion $/ \mathrm{SiO}_{2}$ doped membranes in their study. They have reported that nafion/ $/ \mathrm{SiO}_{2}$ membranes have greater hydrophilicity than hygroscopic oxides/nafion, such as $\mathrm{TiO}_{2}$.

To detemine the effect of $\mathrm{n}-\mathrm{SiO}_{2}$ and $\mathrm{n}-\mathrm{Ag}$ on the thermal behaviors of the c-PVA membrane, DSC thermograms of c-PVA, Ag/c-PVA and $\mathrm{SiO}_{2} / \mathrm{c}-\mathrm{PVA}$ membranes were shown in Figure 1 . From the thermograms, the observed glass transition temperature $\left(T_{\mathrm{g}}\right)$ of c-PVA, Ag/c-PVA and $\mathrm{SiO}_{2} / \mathrm{c}-\mathrm{PVA}$ membranes are seen as $37.22^{\circ} \mathrm{C}, 35.69^{\circ} \mathrm{C}$ and $34.54^{\circ} \mathrm{C}$ respectively. As it is seen that higher $T_{\mathrm{g}}$ value was obtained for c-PVA than that of both Ag/c-PVA and $\mathrm{SiO}_{2} / \mathrm{c}$-PVA membranes. Since polymers with lower $T_{\mathrm{g}}$ possess higher segmental mobility, decrease in $T_{\mathrm{g}}$ suggests an increase in the chain movement and free volume by the possible decrease in the intermolecular interactions. This brings greater availability to the water molecules for the permeation from the membrane material with a lower $T_{\mathrm{g}}$. This results in a higher interaction with water molecules and greater $S_{\mathrm{w}}$ values for $\mathrm{Ag} / \mathrm{c}-\mathrm{PVA}$ and $\mathrm{SiO}_{2} / \mathrm{c}-\mathrm{PVA}$ than c-PVA membranes, which supports the $S_{\mathrm{w}}$ values given by Table 2 .

\subsection{Effect of Sonication on the Characteristics of Ag/c-PVA and $\mathrm{SiO}_{2} / \mathrm{c}-\mathrm{PVA}$ Membranes}

In this part of the study $\mathrm{Ag} / \mathrm{c}-\mathrm{PVA}$ and $\mathrm{SiO}_{2} / \mathrm{c}$-PVA membranes at different thicknesses were supplied to US, as explained in part 2.2, to determine the effect of sonic treatment on the swelling behaviors of crosslinked-composite membranes. Sonication process was performed at room temperature. Table 2 also reflects the swelling behaviors of the US-treated composite membranes. From the results, it can be stated that the sonic-treated composite membranes have considerably greater $S_{\mathrm{w}}$ values than the untreated, i.e., $\mathrm{Ag} / \mathrm{c}-\mathrm{PVA}$ and $\mathrm{SiO}_{2} / \mathrm{c}-\mathrm{PVA}$ membranes. Such an additional increase in the swelling of the membranes indicates that the sonic treated membranes have more available free-volumes for the diffusion of water molecules than the untreated membranes.

In Figure 2, ESCA analyses of Ag/c-PVA and US-Ag/c-PVA membranes were reflected. From the figures, it is seen that there appears a distinct decrease in carbon peak intensity for US-Ag/c-PVA membranes. Similar decrease is also seen in Figure 3, which represents the ESCA analysis of $\mathrm{SiO}_{2} / \mathrm{c}-\mathrm{PVA}$ and US$\mathrm{SiO}_{2} / \mathrm{c}$-PVA membranes, respectively. These results indicate that some of the the loosely held PVA chains which may not chemically bound in polymeric membrane material are likely to be removed by sonication. This could be due to two reasons: (a) PVA chains that are not involved in the crosslinking reactions may be removed from the polymer network by the effect of sonication, or (b) ultrasound may lead to depolymerization of some of the PVA chains with the cleavage of the weakest bonds [5, 17]. Grönroos et al. [28] applied ultrasound to PVA solutions and they have reported that an ultrasonic frequency of $23 \mathrm{kHz}$ leads to the extensive depolymerization of PVA chains by the cleavage of the weakest bonds. Price et al. [54] applied a high intensity US to the suspensions of polyethylene, polypropylene, poly (vinyl chloride) and poly (methyl methacrylate); they have concluded that US results in a change in particle sizes and surface morphology of the materials and also removes some of the material from polyethylene film.

Figure 4 represents the SEM micrographs of US-treated and untreated crosslinked composite membranes. As clear from the micrographs, sonic treatment also affects the surface morphologies of the membranes and causes an increase in surface area of the membranes [55-57], which results in greater interactions of membrane material with the feed. 


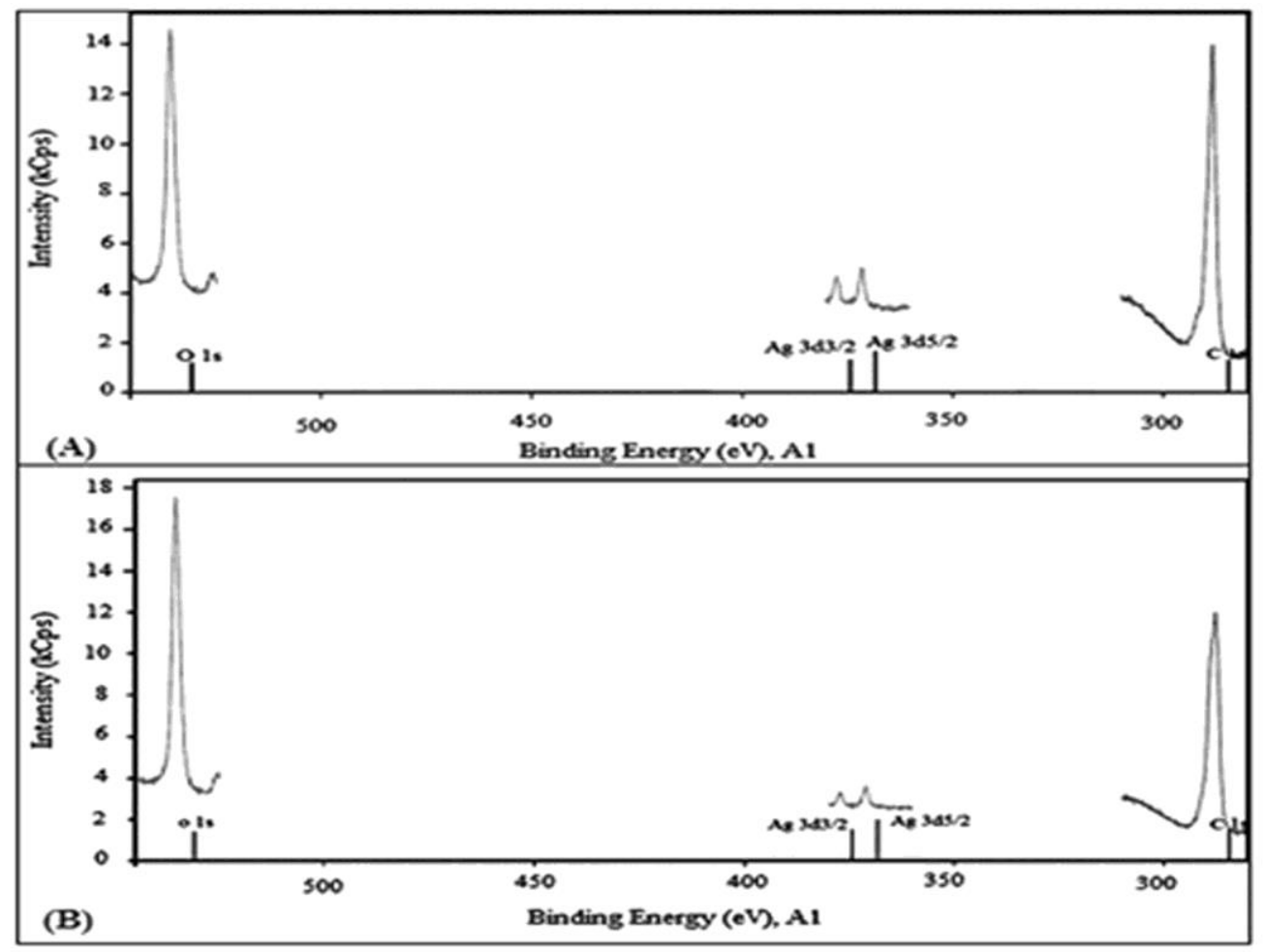

Figure 2. ESCA analysis of (A) Ag/c-PVA and (B) US-Ag/c-PVA membranes

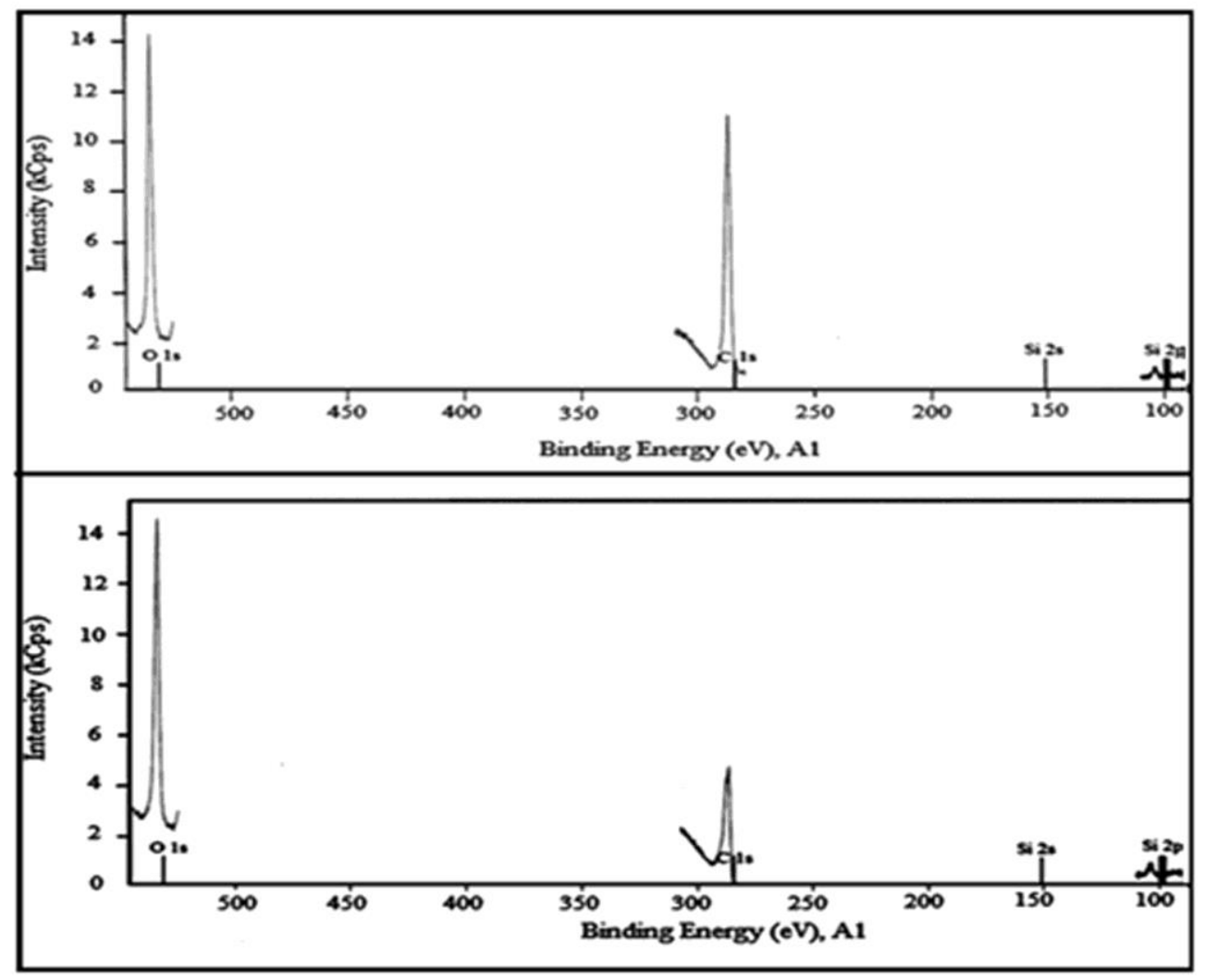

Figure 3. ESCA analysis of (A) $\mathrm{SiO}_{2} / \mathrm{c}-\mathrm{PVA}$ and (B) US-SiO $\mathrm{O}_{2} / \mathrm{c}-\mathrm{PVA}$ membranes 

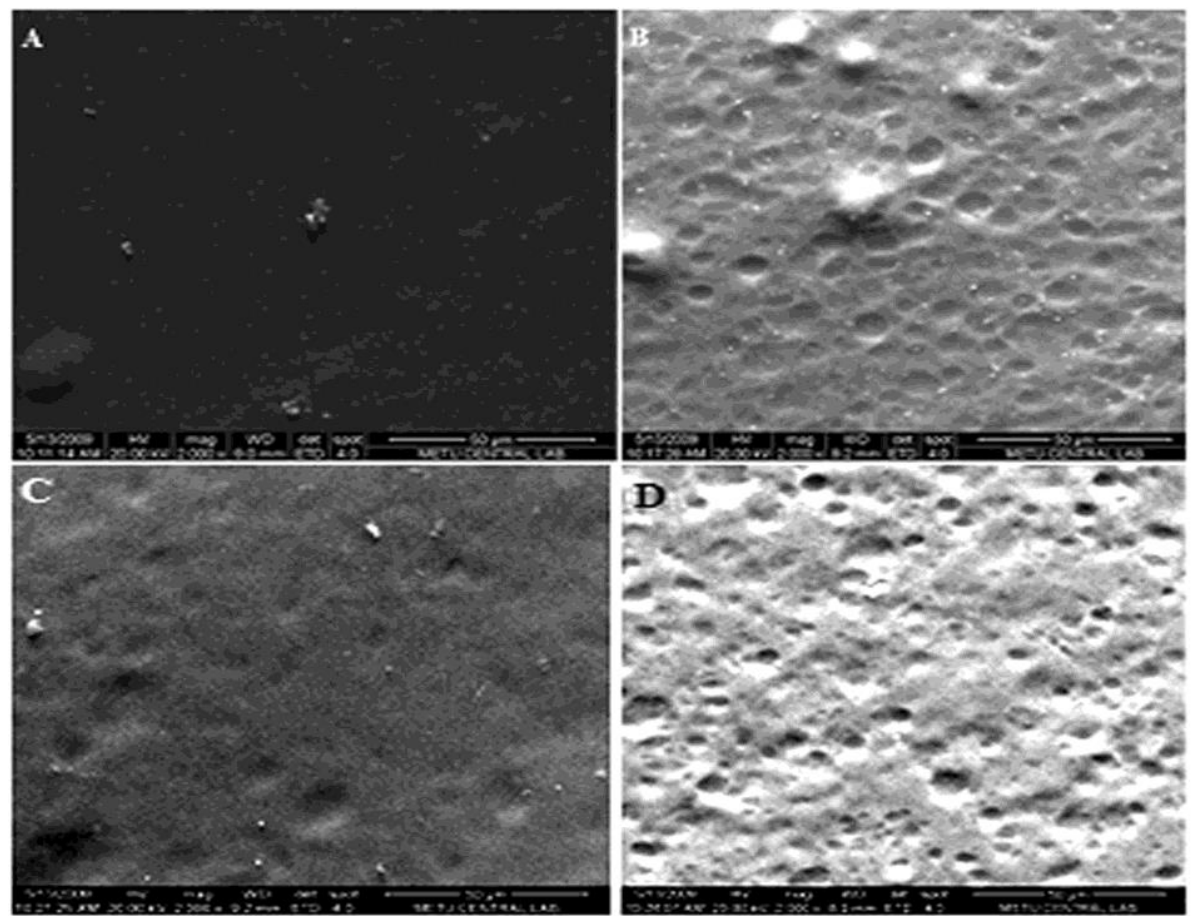

Figure 4. SEM image of (A) Ag/c-PVA (B) US-Ag/c-PVA (C) $\mathrm{SiO}_{2} / c-P V A$ (D) US-SiOz $/ c-P V A$ membranes $(x 2000)$

\subsection{Permeation Capabilities of US-Treated and Untreated Membranes}

To compare the permeation capabilities of the sonic treated and untreated membranes, they were placed in a horizontal diffusion cell and permeation studies were carried out by using aqueous solutions of RB (50 ppm) and $\mathrm{Fe}^{3+}(0.01 \mathrm{M})$, as explained in part 2.4. The results were reflected in Figure 5 as permeant percentages of $\mathrm{RB}$ and $\mathrm{Fe}^{3+}$, by mass.

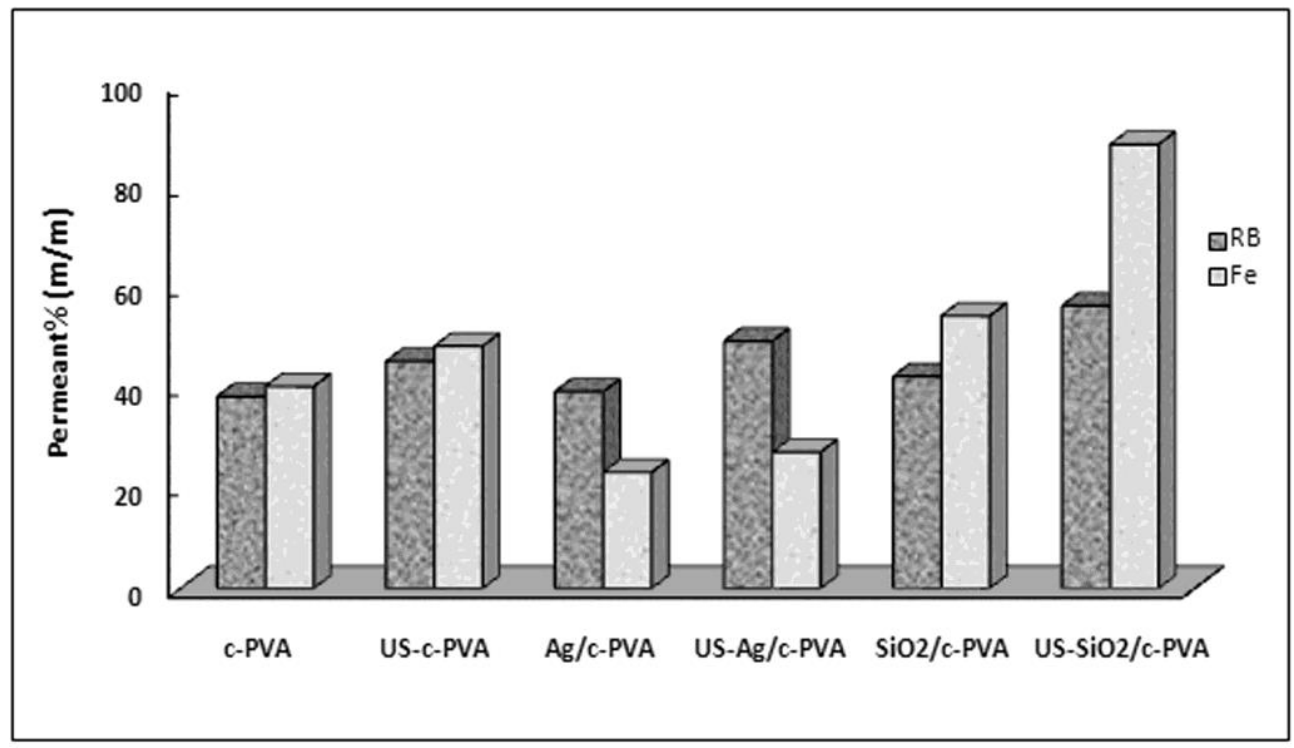

Figure 5. Comparision of the permeation performances of the US-treated and untreated membranes $(\boldsymbol{l}=$ $50 \pm 5 \mu \mathrm{m})$ 
Figure 5 shows that, permeant percentages of $\mathrm{RB}$ and also $\mathrm{Fe}^{3+}$ is greater for both US-c-PVA and US$\mathrm{SiO}_{2} / \mathrm{c}-\mathrm{PVA}$ membranes and an additional increase in permeation of $\mathrm{RB}$ and $\mathrm{Fe}^{3+}$ was obtained in the presence of silicone dioxide. Such a greater permeation is most probably resulted from the hygroscopic property of $\mathrm{SiO}_{2}$.

Merkel et al. [58] have reported an increase in permeability and selectivity by adding nanostructured fumed silica, since silica particles contain polar -OH groups. They have also shown that physical dispersion of nonporous fumed silica particles in glassy amorphous poly (4-methyl-2-pentyne) surprisingly enhances both membrane permeability and selectivity for large organic molecules over small permanent gases. Rodgers et al. [21] prepared silicon dioxide containing nafion membranes to improve their transport properties by using well known hygroscopic properties of silicone dioxide particles.

Figure 5 also shows that, Ag/c-PVA and US-Ag/c-PVA membranes have almost the same permeation for $\mathrm{RB}$ and lower permeations for $\mathrm{Fe}^{3+}$ with respect to both c-PVA and US-c-PVA membranes. In order to clarify the unexpected behavior of Ag-including PVA membranes, interaction of water with the outer layer of the membrane surface was analyzed by contact angle measurements and the results were reflected in Table 3. As it is seen from the table, sonic treated membranes are all have lower contact angles than that of the untreated c-PVA membrane. This confirms the greater sorption tendency and also the greater permeation availability of the US-c-PVA, US-Ag/c-PVA and US-SiO $2 / c-P V A$ than the parent c-PVA membranes since low water contact angle values represent high interactions between the membrane surface and water [59].

Table 3. Water-contact angle values of the membranes

\begin{tabular}{|l|c|}
\hline Membrane & Contact angle $\left(^{\circ}\right)$ \\
\hline c-PVA & $46 \pm 2$ \\
\hline US-c-PVA & $38 \pm 1$ \\
\hline US-Ag/c-PVA & $35 \pm 3$ \\
\hline US-SiO $2 /$ c-PVA & $28 \pm 3$ \\
\hline
\end{tabular}

In addition to the water-contact angle values of the membranes, free volume fractions $(\varepsilon)$ of the membranes which serve as diffusion available fraction of the membranes were also computed by using Equation (2) [60], where $W_{1}$ and $W_{2}$ are the weight of the wet and dry membranes; $D_{\mathrm{w}}$ and $D_{p}$ are the density of water and polymer respectively. $\left(W_{1}-W_{2}\right) / D_{w}$ corresponds to the volume occupied by water molecules and $W_{2} / D_{p}$ is simply the volume of the polymer chains present in the membrane specimen.

$$
\varepsilon=\frac{\frac{W_{1}-W_{2}}{D_{W}}}{\frac{W_{1}-W_{2}}{D_{W}}+\frac{W_{2}}{D_{P}}}
$$

Table 4. Free volume fractions ( $\varepsilon$ of the sonic treated and untreated membranes ( $\boldsymbol{l}=50 \pm 5 \mu \mathrm{m})$

\begin{tabular}{|l|c|l|c|}
\hline Untreated Membranes & $\boldsymbol{\varepsilon} \mathbf{x 1 0 0}$ & US-treated membranes & $\boldsymbol{\varepsilon} \mathbf{x 1 0 0}$ \\
\hline $\mathrm{c}-\mathrm{PVA}$ & 46 & US-c-PVA & 63 \\
\hline $\mathrm{Ag} / \mathrm{c}-\mathrm{PVA}$ & 50 & US-Ag/c-PVA & 65 \\
\hline $\mathrm{SiO}_{2} / \mathrm{c}-\mathrm{PVA}$ & 68 & US-SiO $/ \mathrm{c}-\mathrm{PVA}$ & 73 \\
\hline
\end{tabular}


The calculated free volume fractions of the sonic-treated and untreated membranes were reflected in Table 4. As it is evident from Table 4, the free volume fractions of US-c-PVA, US-Ag/c-PVA and US-SiO $/ 2$ cPVA membranes are all greater than the untreated c-PVA, Ag/c-PVA and $\mathrm{SiO}_{2} / \mathrm{c}-\mathrm{PVA}$ membranes, respectively. So it can be stated that sonic treatment increases the permeation available free volumes of the membranes. Therefore, the lower permeation for the Ag/c-PVA composite membranes, particularly for the permeation of $\mathrm{Fe}^{3+}$, can only be explained by the possible electrostatic repulsive effect of $\mathrm{Ag}[7,61]$.

\section{CONCLUSIONS}

Although the water sorption capacity of the c-PVA membranes can be enhanced by using n-Ag and especially $\mathrm{n}-\mathrm{SiO}_{2}$, this works has clearly shown that ultrasonic treatment is a more efficient method than the use of nanofillers to increase both the permeation capability and sorption tendency of the c-PVA membranes. It can be concluded that ultrasonication is an efficient, environment-friendly, economical, solvent free green membrane modification method to enhance the permeability of water insoluble, crosslinked PVA membranes.

\section{ACKNOWLEDGEMENTS}

The authors would like to thanks Gazi University Research Fund (FEF: 05/2008-04) for financial support.

\section{CONFLICTS OF INTEREST}

No conflict of interest was declared by the authors.

\section{REFERENCES}

[1] Singh, R., Kulkarni, S.G., "Morphological and mechanical properties of poly (vinyl alcohol) doped with inorganic fillers", International Journal of Polymeric Materials and Polymeric Biomaterials, 62: 351-357, (2013).

[2] Asman, G., Sanlı, O., "Separation characteristics of acetic acid--water mixtures using poly(vinyl alcohol-g-4-vinyl pyridine) membranes by pervaporation and temperature difference evapomeation techniques", Journal of Applied Polymer Science, 100: 1385-1394, (2006).

[3] Bui, T.D., Wong, Y., Thu, K., Oh, S.J., Kum Ja, M., Ng, K.C., Raisul, K., Chua, K.J., "Effect of hygroscopic materials on water vapor permeation and dehumidification performance of poly(vinyl alcohol) membranes", Journal of Applied Polymer Science, 134: 44765-44773, (2017).

[4] Kuila, S.B., Ray, S.K., "Dehydration of dioxane by pervaporation using filled blend membranes of poly(vinyl alcohol) and sodium alginate", Carbohydrate Polymers, 101: 1154-1165, (2014).

[5] Zhang, S. Zou, Y. Wei, T. Mu, C. Liu, X., Tong, Z., "Pervaporation dehydration of binary and ternary mixtures of n-butyl acetate, n-butanol and water using PVA-CS blended membranes", Separation and Purification Technology, 173: 314-322, (2017).

[6] Hu, K., Nie, J., Liu, J., Zheng, J., "Separation of methanol from methanol/water mixtures with pervaporation hybrid membranes", Journal of Applied Polymer Science, 128: 1469-1475, (2013).

[7] Singha, N.R., Kar, S., Ray, S.K., "Synthesis of chemically modified poly(vinyl alcohol) membranes for dehydration of dioxane by pervaporation", Separation Science and Technology, 44: 422-446, (2009).

[8] Ghobadi, N., Mohammadi, T., Kasiri, N., Kazemimoghadam, M., "Modified poly(vinyl alcohol)/chitosan blended membranes for isopropanol dehydration via pervaporation: Synthesis 
optimization and modeling by response surface methodology”, Journal of Applied Polymer Science, 134: 44587-44602, (2017).

[9] Li, Y., Yao, S., "High stability under extreme condition of the poly(vinyl alcohol) nanofibers crosslinked by glutaraldehyde in organic medium", Polymer Degradation and Stability, 137: 229-237, (2017).

[10] Asman, G., Sanl1, O., "Separation of acetic acid-water mixtures through poly(vinyl alcohol)/poly(acrylic acid) alloy membranes by using evapomeation and temperature difference evapomeation methods", Separation Science and Technology, 41: 1193-1209, (2006).

[11] Xia, L.L., Li, C.L., Wang, Y., "In-situ crosslinked PVA/organosilica hybrid membranes for pervaporation separations", Journal of Membrane Science, 498: 263-275, (2016).

[12] Zhang, Q., Li, B., Sun, D., Zhang, L., Li, D., Yang, P., "Preparation and characterization of PVA membrane modified by water-soluble hyperbranched polyester (WHBP) for the dehydration of nbutanol”, Journal of Applied Polymer Science, 133: 43533-43542, (2016).

[13] Sukhlaaied, W., Riyajan, S., "Green robust $\mathrm{pH}$-temperature-sensitive maleated poly(vinyl alcohol)-ggelatin for encapsulated capsaicin”, Polymer Bulletin, 73: 2303-2320, (2016).

[14] Jayadevan, J., Alex, R., Gopalakrishnapanicker, U., "Chemically modified natural rubber latexpoly(vinyl alcohol) blend membranes for organic dye release", Reactive and Functional Polymers, 112: 22-32, (2017).

[15] Mallakpour, S., Jarahiyan, A., "Utilization of ultrasonic irradiation as a green and effective strategy to prepare poly( $N$-vinyl-2-pyrrolidone)/modified nano-copper (II) oxide nanocomposites", Ultrasound Sonochemistry, 37: 128-135, (2017).

[16] Ng, L.Y., Leo, C.P., Mohammad, A.W., "Optimizing the incorporation of silica nanoparticles in polysulfone/poly (vinyl alcohol) membranes with response surface methodology", Journal of Applied Polymer Science, 121: 1804-1814, (2011).

[17] Asman, G., Kaya, M., Bayramgil, N.P., "Effect of sonic treatment on the permeation performance of cellulose acetate membranes modified by n-SiO 2 ", Turkish Journal of Chemistry, 39: 297-305, (2015).

[18] Semsarzadeh, M.A., Ghalei, B., "Preparation, characterization and gas permeation properties of polyurethane-silica/poly(vinyl alcohol) mixed matrix membranes", Journal of Membrane Science, 432: 115-125, (2013).

[19] Zhang, L., Chen, X., Zeng, C., Xu, N., "Preparation and gas separation of nano-sized nickel particlefilled carbon membranes", Journal of Membrane Science, 281: 429-434, (2006).

[20] Jiang, X., Luo, Y., Hou, L., Zhao, Y., "The effect of glycerol on the crystalline, thermal, and tensile properties of $\mathrm{CaCl}_{2}$-doped starch/PVA films", Polymer Composites, 37: 3191-3199, (2016).

[21] Rodgers, M.P., Shi, Z., Holdcroft, S., "Transport properties of composite membranes containing silicon dioxide and nafion", Journal of Membrane Science, 325: 346-356, (2008).

[22] Shi, J.J., Yang, E.L., "Green electrospinning and crosslinking of polyvinyl alcohol/ citric acid", Journal of Nano Research, 32: 32-42, (2015).

[23] Lin, X., Gong, M., Liu, Y., Wu, L., Li, Y., Liang, X., Li, Q., Xu, T., “A convenient, efficient and green route for preparing anion exchange membranes for potential application in alkaline fuel cells", Journal of Membrane Science, 425-426: 190-199, (2013). 
[24] Singh, S., Jasti, A., Kumar, M., Shahi, V.K., "A green method for the preparation of highly stable organic-inorganic hybrid anion-exchange membranes in aqueous media for electrochemical processes", Polymer Chemistry, 1: 1302-1312, (2010).

[25] Zhu, H., Du, M., Zhang, M., Wang, P., Bao, S., Fu, Y., Yao, J., "Fecile and green fabrication of small, mono-disperse and size-controlled noble metal nanoparticles embedded in water-stable polyvinyl alcohol nanofibers: High sensitive, flexible and reliable materials for biosensors", Sensors and Actuators B: Chemical, 185: 608-619, (2013).

[26] Vatanpour, V., Shockravi, A., Zarrabi, H., Nikjavan, Z., Javadi, A., "Fabrication and characterization of anti-fouling and anti-bacterial Ag-loaded graphene oxide/polyethersulfone mixed matrix membrane", Journal of Industrial and Engineering Chemistry, 30: 342-352, (2015).

[27] Lu, X., Zou, X., Li, C., Zhong, Q., Ding, W., Zhou, Z., "Green electrochemical process solid-oxide oxygen-ion-conducting membrane (SOM): Direct extraction of Ti-Fe alloys from natural ilmenite", Metallurgical and Materials Transactions B, 43: 503-512, (2012).

[28] Grönroos, A., Pirkonen, P., Heikkinen, J., Ihalainen, J., Mursunen, H., Sekki, H., "Ultrasonic depolymerization of aqueous polyvinyl alcohol”, Ultrasonic Sonochemistry, 8: 259-264, (2001).

[29] Shchukin, D., Skorp, E., Belova, V., Möhwald, H., "Ultrasonic cavitation at solid surfaces", Advanced Materials, 23: 1922-1934, (2011).

[30] Tung, K.L., Teoh, H.C., Lee, C.W., Chen, C.H., Li, Y.L., Lin, Y.F., Chen, C.L., Huang, M.S., "Characterization of membrane fouling distribution in a spiral wound module using high-frequency ultrasound image analysis", Journal of Membrane Science, 495: 489-501, (2015).

[31] Gómez Álvarez-Arenas, T.E., Apel, P.Y., Orelovitch, O.L., Muñoz, M., "New ultrasonic technique for the study of the pore shape of track-etched pores in polymer films", Radiation Measurements, 44: 11141118, (2009).

[32] Wang, X., Li, X., Fu, X., Chen, R., Gao, B., "Effect of ultrasound irradiation on polymeric microfiltration membranes", Desalination, 175: 187-196, (2005).

[33] Li, Y.S., Shi, L.C., Gao, X.F., Huang, J.G., "Cleaning effects of oxalic acid under ultrasound to the used reverse osmosis membranes with an online cleaning and monitoring system", Desalination, 390: 62-71, (2016).

[34] Luján-Facundo, M.J., Mendoza-Roca, J.A., Cuartas-Uribe, B., Álvarez-Blanco, S., "Cleaning efficiency enhancement by ultrasounds for membranes used in dairy industries", Ultrasonics Sonochemistry, 33: 18-25, (2016).

[35] Yu, W., Graham, N., Liu, T., "Effect of intermittent ultrasound on controlling membrane fouling with coagulation pre-treatment: Significance of the nature of adsorbed organic matter", Journal of Membrane Science, 535: 168-177, (2017).

[36] Aliasghari-Aghdam, M., Mirsaeedghazi, H., Aboonajmi, M., Kianmehr, M.H., "Effect of ultrasound on different mechanisms of fouling during membrane clarification of pomegranate juice", Innovative Food Science and Emerging Technologies, 30: 127-131, (2015).

[37] Cai, M., Li, W., Liang, H., "Effects of ultrasound parameters on ultrasound-assisted ultrafiltration using cross-flow hollow fiber membrane for radix astragalus extracts", Chemical Engineering and Processing, 86: 30-35, (2014). 
[38] Augustine, A., Raduzan, J., Asma, Y., Afeez, G., Azza, A., "Comparative study of continuous and intermittent ultrasonic ultrafiltration membrane for treatment of synthetic produced water containing emulsion", Chemical Engineering and Processing, 132: 137-147, (2018).

[39] Qasim, M., Darwish, N.N., Mhiyo, S., Darwish, N.A., Hilal, N., "The use of ultrasound to mitigate membrane fouling in desalination and water treatment", Desalination, 443: 143-164, (2018).

[40] Masselin, I., Chasseray, X., Durand-Bourlier, L., Lainé, J.M., Syzaretc, P.Y., Lemordant, D., "Effect of sonication on polymeric membranes", Journal of Membrane Science, 181: 213-220, (2001).

[41] Wang, R., Ma, M., Yan, Y., Wang, Z., "Ultrasonic-assisted fabrication of high flux t-type zeolite membranes on alumina hollow fibers", Journal of Membrane Science, 548: 676-684, (2018).

[42] Julian, T.N., Zentner, G.M., "Ultrasonically mediated solute permeation through polymer barriers", Journal of Pharmacy and Pharmacology, 38: 871-877, (2011).

[43] Kost, J., Leong, K., Langer, R., "Ultrasound-enhanced polymer degradation and release of incorporated substances", National Academi of Science, 86: 7663-7666, (1989).

[44] Taskın, G., Sanl1, O., Asman, G. "Swelling assisted photografting of itaconic acid onto sodium alginate membranes”, Applied Surface Science, 257: 9444-9450, (2011).

[45] Galiona, F. “Casting Solutions”, Encyclopedia of Membranes, ISBN: 978-3-642-40872, (2014).

[46] Mohammadi, F., Rabiee, A. "Solution casting, characterization and performance, evaluation of perfluorosulfonic sodium type membranes for chlor-alkali application", Journal of Applied Polymer Science, 120: 3469-3476 (2011).

[47] Chuang, W.Y., Young, T.H., Chiu, W.Y., "The effect of acetic acid on the structure and filtration properties of poly(vinyl alcohol) membranes", Journal of Membrane Science, 172: 241-251, (2000).

[48] Sitter, K.D., Winberg, P., Haend, J.D., Dotremont, C., Leysen, R., Martens, J.A., Mullens, S., Maurer, F.H.J., Vancelecom, I.F.J., "Silica filled poly [1-(trimethyl silyl-1-propyne nanocomposite membranes: Relation between the transport of gases and structural characteristics", Journal of Membrane Science, 278: 83-91, (2006).

[49] Heaney, P.J., Prewitt, C.T., Gibbs, G.V. "Silica - Physical behavior, geochemistry and materials applications", Reviews in Mineralogy, 29: Mineralogical Society of America, (1994).

[50] Wang, C.B., Deo, G., Wachs, I.E. "Interaction of polycrystalline silver with oxygen, water, carbon dioxide, ethylene, and methanol: In situ raman and catalytic studies", Journal of Physical Chemistry B, 103: 5645-5656, (1999).

[51] Bi, C., Zhang, H., Zhang, Y., Zhu, X., Ma, Y., Dai, H., Xiao, S., "Fabrication and investigation of $\mathrm{SiO}_{2}$ supported sulfated zirconia/nafion self-humidifying membrane for proton exchange membrane fuel cell applications", Journal of Power Source, 184:197-203, (2008).

[52] Meng, F., Sun, Z.A., "Mechanism for enhanced hydrophilicity of silver nanoparticles modified $\mathrm{TiO}_{2}$ thin films deposited by RF magnetron sputtering”, Applied Surface Science, 255: 6715-6720, (2009).

[53] Watanabe, M., Uchida, H., Seki, Y., Emori, M., Stonehart, P., "Self-humidifying polymer electrolyte membranes for fuel cells", Journal of Electrochemical Society, 143: 3847-3852, (1996).

[54] Price, G.J., White, A.J., Clifton, A.A., "The effect of high-intensity ultrasound on solid polymers", Polymer, 36: 4919-4925, (1995). 
[55] Franco, F., Pérez-Maqueda, L.A., Pérez-Rodríguez, J.L. "The effect of ultrasound on the particle size and structural disorder of a well-ordered kaolinite", Journal of Colloid Interface Science, 274(1): 107$117,(2004)$.

[56] Price, G.J., White, A.J., Clifton, A.A. "The effect of high-intensity ultrasound on solid polymers", Polymer, 36(29): 4919-4925, (1995).

[57] Asman, G., Kaya, M., Bayramgil, N. "Effect of sonic treatment on the permeation performance of cellulose acetate membranes modifie by n-SiO2 Turkish Journal of Chemistry, 39: 297-305, (2015).

[58] Merkel, T.C., Freeman, B.D., Spontak, R.J., He, Z., Pinnau, I., Meakin, P., Hill, A.J., "Ultrapermeable reverse-selective nanocomposite membranes", Science, 296: 519-522, (2002).

[59] Asman, G., "Use of poly (methyl methacrylate-co-methacrylic acid) membranes in ultrafiltration of aqueous $\mathrm{Fe}^{3+}$ solutions by complexing with poly (vinyl pyrrolidone) and dextran", Separation Science and Technology, 44: 1164-1180, (2009).

[60] Feng, C., Shi, B., Li, G., Wu, Y., "Preparation and properties of microporous membrane from poly(vinylidene fluoride-co-tetrafluoroethylene) (F2.4) for membrane distillation", Journal of Membrane Science, 237: 15-24, (2004).

[61] Mimoune, S., Belazzougui, R.E., Amrani, F., "Purification of aqueous solutions of metal ions by ultrafiltration", Desalination, 217: 251-259, (2007). 